July 2009

\title{
Spinal Cord Ependymomas
}

\author{
Teresita DeVera BSN, RN, CNRN
}

Carol Blyzniuk BSN, RN

Follow this and additional works at: https://jdc.jefferson.edu/jhnj

\section{Let us know how access to this document benefits you}

\section{Recommended Citation}

DeVera, Teresita BSN, RN, CNRN and Blyzniuk, Carol BSN, RN (2009) "Spinal Cord Ependymomas," JHN Journal: Vol. 4 : Iss. 3 , Article 1.

DOI: https://doi.org/10.29046/JHNJ.004.3.001

Available at: https://jdc.jefferson.edu/jhnj/vol4/iss3/1

This Article is brought to you for free and open access by the Jefferson Digital Commons. The Jefferson Digital Commons is a service of Thomas Jefferson University's Center for Teaching and Learning (CTL). The Commons is a showcase for Jefferson books and journals, peer-reviewed scholarly publications, unique historical collections from the University archives, and teaching tools. The Jefferson Digital Commons allows researchers and interested readers anywhere in the world to learn about and keep up to date with Jefferson scholarship. This article has been accepted for inclusion in JHN Journal by an authorized administrator of the Jefferson Digital Commons. For more information, please contact: JeffersonDigitalCommons@jefferson.edu. 


\section{Spinal Cord Ependymomas}

\section{Teresita J. DeVera, BSN, RN, CNRN, Carol A. Blyzniuk, BSN, RN}

Department of Neurological Surgery, Jefferson University Physicians, Philadelphia, PA

\section{Introduction}

Intradural or primary spinal cord tumors (SCT) are rare. However, when these lesions grow, compression of the spinal cord can lead to limb dysfunction, motor or sensory loss, and possibly death. Ependymomas are believed to account for $60 \%$ of all primary neoplasms of the spinal cord and filum terminale. A vast majority of spinal cord ependymomas are benign and not considered malignant (cancer). This poster presentation will describe the presentation, physical exam findings, and imaging of patients with a spinal cord ependymoma. It will focus on the nursing implications of thorough assessment and timely intervention for a more positive outcome for the patient and family.

\section{Pathophysiology}

Ependymomas can be located intraparenchymal either in the cervical or thoracic cord or at the caudal end of the spinal cord, conus medullaris, or filum terminale. There are two major types, and both intramedullary and myxopapillary subtypes tend to grow slowly. They are usually well differentiated and encapsulated. Ependymomas arise from the central canal ependymal cells. As they enlarge, they grow circumferentially, displacing spinal tissues in all directions. Neurologic dysfunction develops as the tumor enlarges and compresses adjacent healthy neural tissue.

\section{Diagnostic Evaluation}

Patients who present with symptoms suggestive of spinal cord dysfunction should undergo a physical examination. Pain is the most common presenting symptom and is often localized to spine (65\%) where the duration of symptoms is typically extensive. This axial spinal column pain typically worsens at night or upon awakening. Common clinical signs of spinal cord tumors are weakness of the limbs caudal to the spinal levels of involvement, and gait abnormalities such as a spastic paraparesis or ataxia.
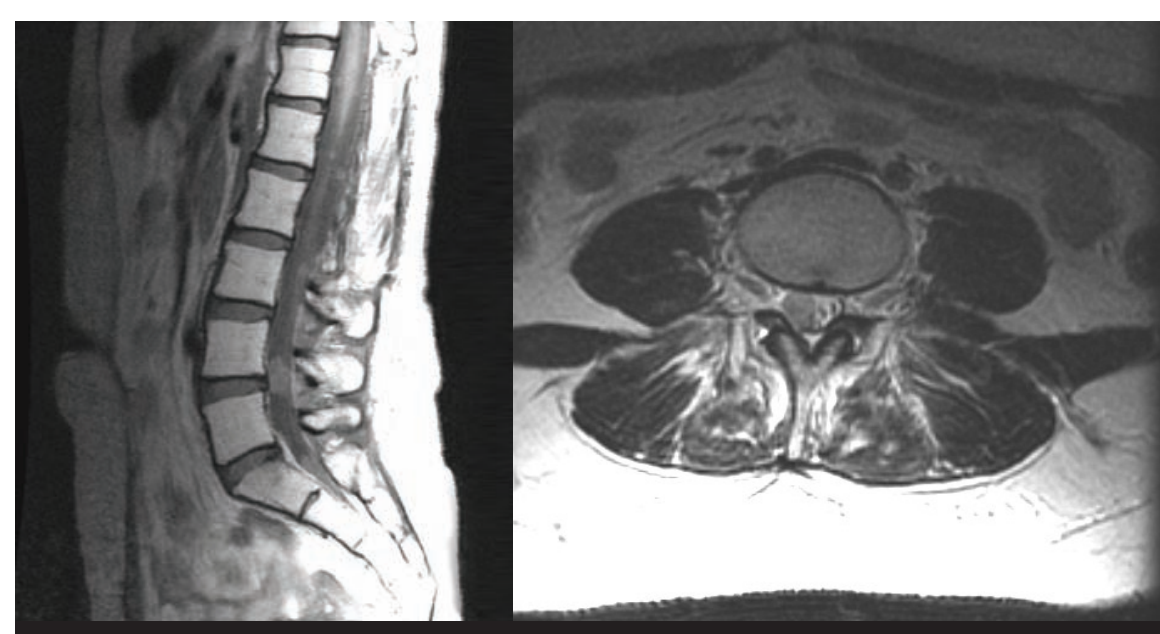

Figure 1

T1-weighted images - Isotense signal with spinal cord

T2-weighted images - Hyperintense signal

Strong homogenous enhancement with contrast
Physical examination may also reveal reflex abnormalities, sensory changes, and sphincter dysfunction and paraspinal muscle spasms. Plain x-rays do not image the spinal cord. Myelography, with computed tomography scan, is an invasive exam requiring a needle lumbar puncture to withdraw CSF and dispense contrast media into the subarachnoid space, and will indirectly identify the tumor. MRI is the gold standard, for detailed assessment of intrinsic spinal pathology and should be performed with gadolinium.

\section{Treatment}

Treatment for ependymomas is surgical resection. Advances in technology have aided in the ability to do a more extensive resection. The use of somatosensory evoked potentials (SSEP) during surgery correlates with improved prognosis. A postoperative MRI is recommended to assess for presence of residual tumor and to facilitate adjuvant treatment. Radiotherapy, often recommended if there is a subtotal resection, can be utilized to decrease the incidence of recurrences by controlling the growth of macroscopic tumor cells. Spinal cord ependymoma patients have the best outcomes of all intramedullary spinal neoplasm due to the lack of infiltration into the parenchyma and the presence of a capsule which aids in a total resection.

\section{Nursing Implications}

A person diagnosed with a spinal cord tumor will often wonder, "Is it cancer?" or "Am I going to die?" Frequently, patients may feel the need to "treat the cancer" immediately or make decisions right away. Others may feel scared, uncertain, or confused about what the diagnosis may entail.

Patients must have an understanding of the treatment goals and plan of care. The key step in management is their timely diagnosis and treatment. Once neurological function is lost, it is unlikely that function will return or recover. Surgical expectations include post-operative pain as well as new neurological deficits obtained as a result of the resection. Patient education should focus on the importance of long-term management that includes serial neurological examinations and MRI to assess 


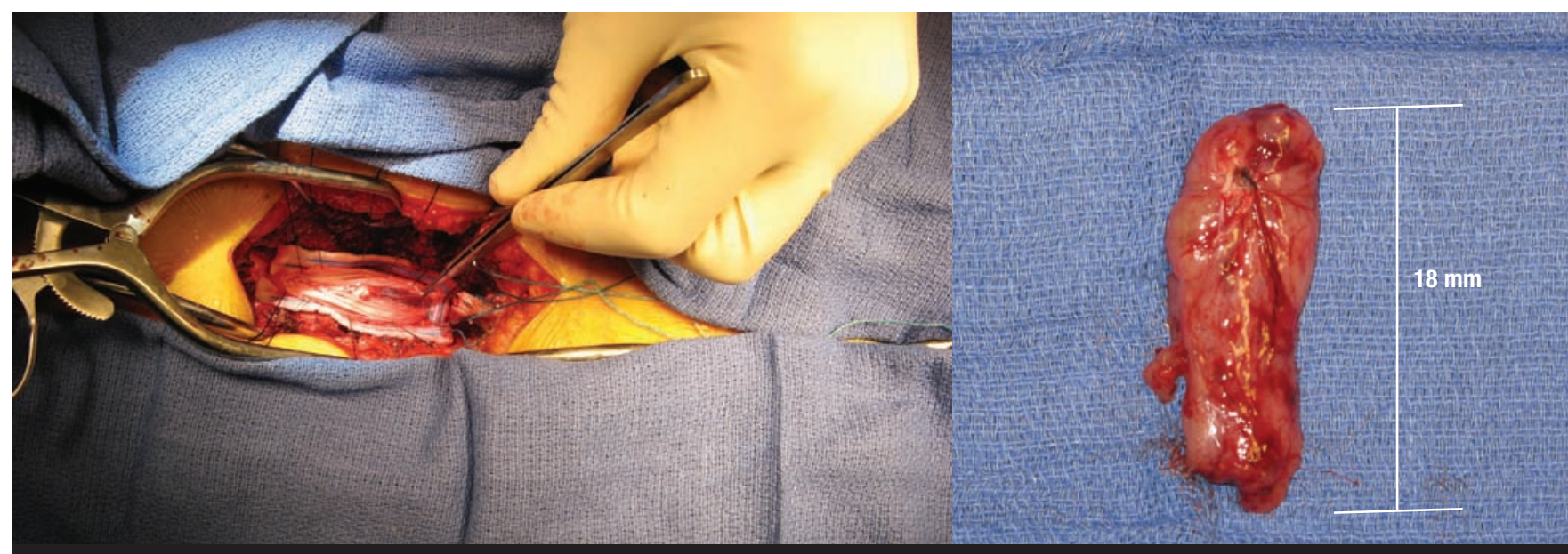

Figure 2

(a) Intraoperative view of lumbar ependymoma resection and (b) an ependymoma after resection complete

for recurrence or progressive growth or residual tumor. Patients should understand that any further deterioration from initial treatment is an emergency and warrants immediate intervention.

Neurosurgical nurses can play a vital role in creating a positive patient outcome. In both the inpatient and outpatient settings, the nurse is frequently the link between the patient and the neurosurgeon as well as other important providers within the healthcare team. Nurses must be able to effectively communicate the problem, coordinate a plan of care, and implement it based on the patient's baseline history and exam.

\section{References}

1. Robles, S.G., et al. (2005) Intradural extramedullary spinal ependymoma: a benign pathology? Spine, 30 (9), pp. E251-E254.

2. Harrop, J.S., Benzel, E.C. (2002). Intraspinal neoplasms. In J.W. Frymoyer et al (Eds), Adult and pediatric spine (3rd ed.) pp. 289-301. Philadelphia: Lippincott Willaims \& Wilkins.

3. Lee, J. et al. (2006). Clinical management of intramedullary spinal ependymomas in adults. Neurosurgery Clinics of North America, 17 (1), pp.21-27.

The Thomas Jefferson University Department of Neurological Surgery will be presenting three of the designated "Top Ten" abstracts at the Congress of Neurological Surgeons annual meeting held in New Orleans, October 24-29 2009.

Two of these studies address controlling complications, which is not only good for the patient but also helps limit expenditures arising from extra procedures and longer lengths of stay:

- Potential Financial Impact of Restriction in "Never Event" and Periprocedural Hospital-Acquired Condition Reimbursement at a Tertiary Neurosurgical Center

- Are Ventriculostomy Infections Reduced by Standardized Protocols or by AntibioticImpregnated Catheters?

The third is exploring the frontiers of technology that will be used to benefit patients:

- An Evaluation of Neuroplasticity and Behavior with Deep Brain Stimulation in the Nucleus Accumbens of the Rat 